\title{
Interfacial Charge Transfer Anisotropy in Polycrystalline Lead lodide Perovskite Films
}

\author{
Jun Yin, ${ }^{\dagger}$ Daniele Cortecchia, ${ }^{\ddagger}, \S$ Anurag Krishna, ${ }^{\ddagger}$ Shi Chen, ${ }^{\dagger}$ Nripan Mathews, ${ }^{\S}$ Andrew C. Grimsdale, ${ }^{\S, \|}$ \\ and Cesare Soci* ${ }^{* \dagger}$ \\ ${ }^{\dagger}$ Division of Physics and Applied Physics, School of Physical and Mathematical Sciences, Nanyang Technological University, 21 \\ Nanyang Link, Singapore 637371 \\ ${ }^{\ddagger}$ Interdisciplinary Graduate School, Nanyang Technological University, 50 Nanyang Avenue, Singapore 639798 \\ ${ }^{\S}$ Energy Research Institute @ NTU (ERI@N), Research Techno Plaza, Nanyang Technological University, 50 Nanyang Drive, \\ Singapore 637553 \\ "School of Materials Science and Engineering, Nanyang Technological University, 50 Nanyang Avenue, Singapore 639798
}

\section{Supporting Information}

ABSTRACT: Solar cells based on organic-inorganic lead iodide perovskite $\left(\mathrm{CH}_{3} \mathrm{NH}_{3} \mathrm{PbI}_{3}\right)$ exhibit remarkably high power conversion efficiency (PCE). One of the key issues in solution-processed films is that often the polycrystalline domain orientation is not welldefined, which makes it difficult to predict energy alignment and charge transfer efficiency. Here we combine ab initio calculations and photoelectron spectroscopy to unravel the electronic structure and charge redistribution at the interface between different surfaces of $\mathrm{CH}_{3} \mathrm{NH}_{3} \mathrm{PbI}_{3}$ and typical organic hole acceptor Spiro-OMeTAD and electron acceptor PCBM. We find that both hole and electron interfacial transfer depend strongly on the $\mathrm{CH}_{3} \mathrm{NH}_{3} \mathrm{PbI}_{3}$ surface orientation: while the (001) and (110) surfaces tend to favor hole injection to Spiro-OMeTAD, the (100) surface facilitates electron transfer to PCBM due to surface delocalized charges and hole/electron accumulation at the $\mathrm{CH}_{3} \mathrm{NH}_{3} \mathrm{PbI}_{3}$ /organic interfaces. Molecular dynamic simulations indicate that this is due to strong orbital interactions under thermal fluctuations at room temperature, suggesting the possibility to

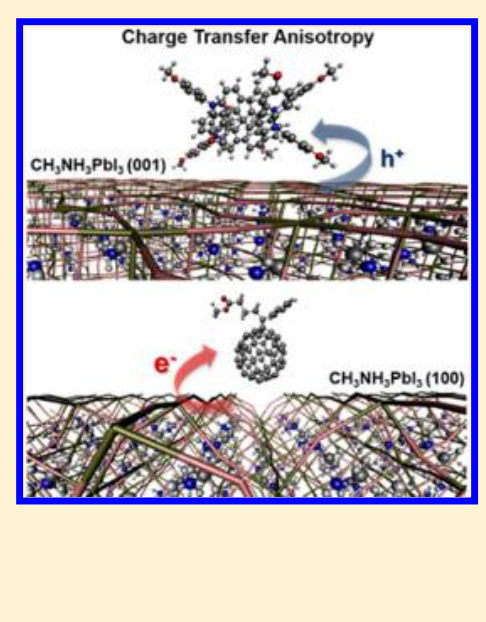
further improve charge separation and extraction in perovskite-based solar cells by controlling perovskite film crystallization and surface orientation.

$\mathrm{T}$ he combination of solution-processable methylammonium metal halide perovskites, such as the lead iodide perovskite $\left(\mathrm{CH}_{3} \mathrm{NH}_{3} \mathrm{PbI}_{3}\right)$, with organic materials such as the electron acceptor PCBM $\left([6,6]\right.$-phenyl- $\mathrm{C}_{61}$-butyric acid methyl ester) or the hole acceptor Spiro-MeOTAD $\left(2,2^{\prime}, 7,7^{\prime}\right.$-tetrakis( $N, N$-di- $p$-methoxyphenylamine)-9,9'-spirobifluorene) has opened new avenues to high-efficiency, low-cost, third generation photovoltaic devices. These devices operate similarly to solid-state dye-sensitized solar cells, in that the $\mathrm{CH}_{3} \mathrm{NH}_{3} \mathrm{PbI}_{3}$ sensitizer doubles as light absorber and charge carrier transporter. ${ }^{1,2}$ The power conversion efficiency (PCE) of perovskite-based solar cells has increased impressively from 3.8 to more than $20 \%$ in just a few years. ${ }^{3-7}$ These highly efficient conversions can be related mainly to the ambipolar properties ${ }^{8}$ and long electron and hole diffusion lengths observed in perovskite materials. ${ }^{9,10}$ Although bulk properties of perovskites are prerequisite for their good photovoltaic performance, surface passivation, interfacial structure and band alignment between the perovskite and carrier transporting layers are also critical for achieving efficient carrier transport and charge extraction. ${ }^{11}$ Recent studies on the electrical potential distribution within mesoporous solar cells highlighted its similarities to $p-i-n$ type junctions, confirming the importance of optimization of charge transfer from the perovskite toward both electron and hole transporting materials. ${ }^{12}$

Crystallization and morphology control of solution-processed perovskite active layers through solvent engineering techniques are of paramount importance, ${ }^{7}$ as they determine key factors affecting photovoltaic performance ${ }^{13}$ such as optical absorption, ${ }^{14}$ interfacial energetics, ${ }^{15}$ exciton diffusion length, and charge carrier mobility. ${ }^{16}$ The highest PCE of $\sim 19.3 \%$ was achieved in a planar geometry by controlling the formation of perovskite crystals in the layer and carefully choosing charge transporting materials. ${ }^{5}$ Most recently, large single crystals with millimeter-scale size were obtained by vapor-assisted crystallization and solution-based hot-casting, ${ }^{17,18}$ yielding extremely low trap state density and long carrier diffusion. Although several effects of perovskite crystallinity on charge transport properties have been identified, its influence on interfacial charge transfer has not yet been discussed.

The present work aims to understand the interfacial energetics of organic/polycrystalline $\mathrm{CH}_{3} \mathrm{NH}_{3} \mathrm{PbI}_{3}$ systems

Received: February 28, 2015

Accepted: March 30, 2015 


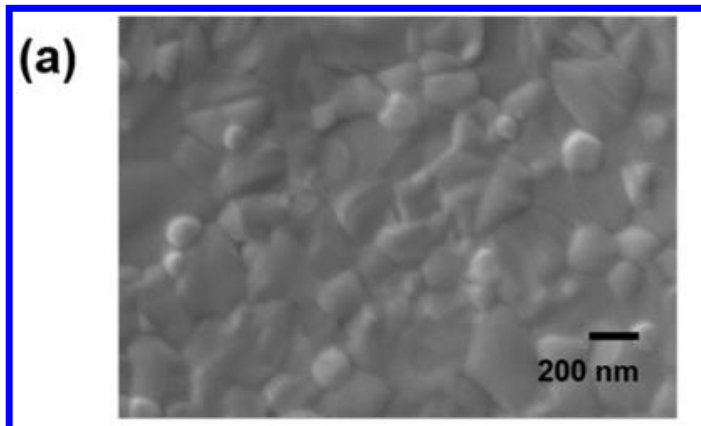

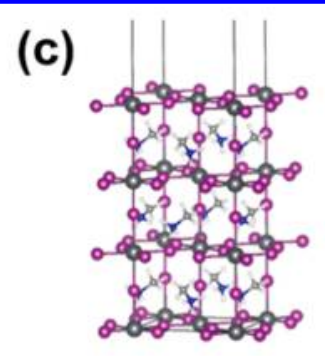

(001)

(d)

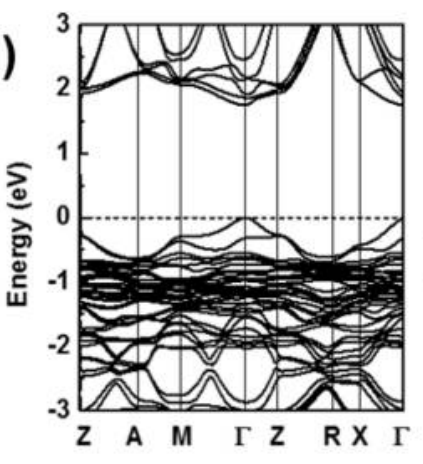

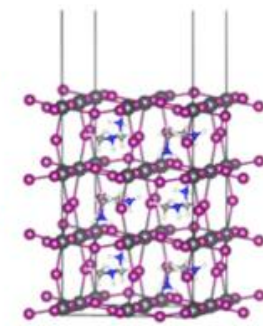

(110)

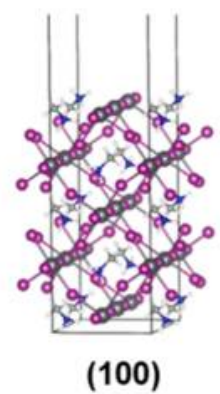

(100)
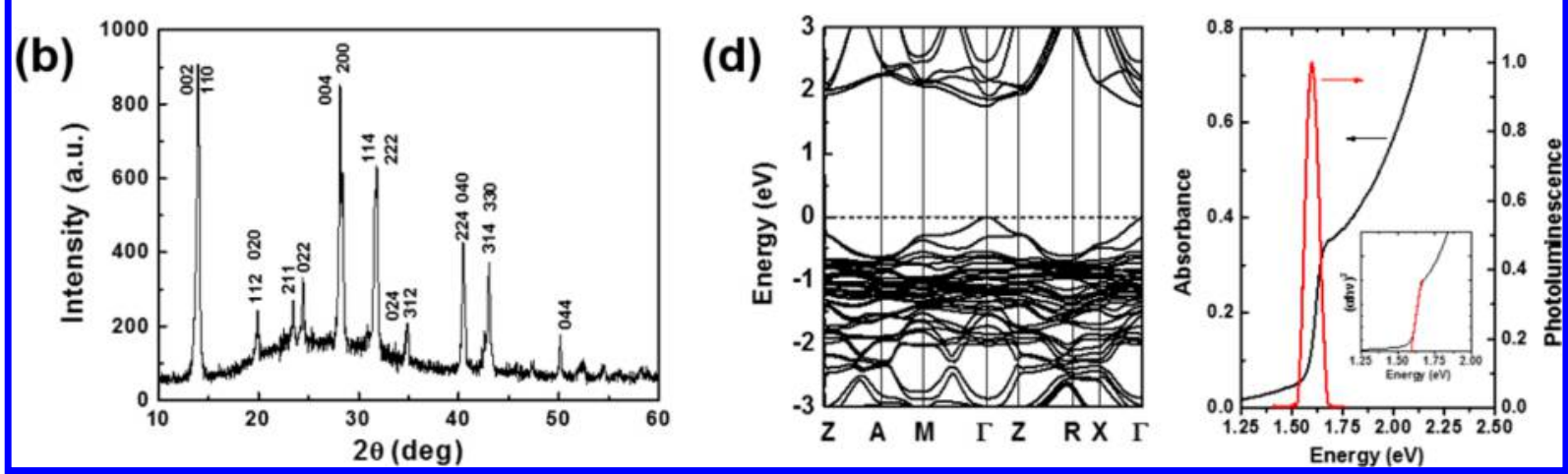

Figure 1. Morphology, structure and optoelectronic properties of $\mathrm{CH}_{3} \mathrm{NH}_{3} \mathrm{PbI}_{3}$ thin films. (a) Top-view SEM image of the polycrystalline film; (b) $\mathrm{XRD}$ pattern, indicating a single-phase sample with tetragonal phase at room temperature; (c) side-view of tetragonal $\mathrm{CH}_{3} \mathrm{NH}_{3} \mathrm{PbI}_{3}$ slabs along the direction (001), (100) and (110); (d) calculated band structure and measured absorption and photoluminescence spectra (insert: Tauc plot of the absorption spectrum).

from ultraviolet photoelectron spectroscopy (UPS) measurements, and the effects of perovskite surface orientation on the electronic properties and charge transfer and redistribution at hybrid organic/perovskite interfaces from theoretical point of view. We have investigated ground state electronic properties, charge transfer and redistribution at the hybrid interfaces between $\mathrm{CH}_{3} \mathrm{NH}_{3} \mathrm{PbI}_{3}$ and organic charge transporting materials (Spiro-OMeTAD and PCBM) by first-principle DFT and molecular dynamics. The simulation results favorably compare to UPS measurements of the electronic band gap, valence band and work function (WF) of $\mathrm{CH}_{3} \mathrm{NH}_{3} \mathrm{PbI}_{3}$ absorber materials, as well as heterojunctions with SpiroOMeTAD and PCBM. We find that $\mathrm{CH}_{3} \mathrm{NH}_{3} \mathrm{PbI}_{3}$ surface orientation strongly affects hole/electron injection behavior toward hole and electron charge transfer layers. The estimated interfacial dipoles induced by hole and electron accumulation layers appearing at the $\mathrm{CH}_{3} \mathrm{NH}_{3} \mathrm{PbI}_{3}$ surfaces were used to quantitatively estimate the charge transfer yield and determine the most favorable surface polarity to each of the charge carriers: with PCBM and Spiro-OMeTAD, electron transfer is enhanced on polar surfaces, while hole transfer yield is higher on nonpolar surfaces. We believe that similar interfacial model and theoretical predictions are likely to apply to a wide range of organic/perovskite interfaces, suggesting that control of perovskite crystallization and surface orientation should be regarded as key design parameters to optimize performance of hybrid perovskite solar cells.

$\mathrm{CH}_{3} \mathrm{NH}_{3} \mathrm{PbI}_{3}$ thin films were prepared by single-step spincoating of the precursors $\mathrm{CH}_{3} \mathrm{NH}_{3} \mathrm{I}$ and $\mathrm{PbI}_{2}$, a common deposition method used to fabricate photovoltaic devices. ${ }^{13}$ The resulting films are polycrystalline, and show tetragonal phase domains similar to bulk crystal powders (Figure 1a). Comparison of XRD measurements of $\mathrm{CH}_{3} \mathrm{NH}_{3} \mathrm{PbI}_{3}$ thin films with bulk indicate weak preferential orientation toward the (001) directions relative to the substrate plane (Figure 1b). To understand the spontaneous formation of polycrystalline domains, we first optimized the crystal structure of the $\mathrm{CH}_{3} \mathrm{NH}_{3} \mathrm{PbI}_{3}$ tetragonal crystal using experimental cell parameters and coordinates as starting values (space group $\mathrm{I} / \mathrm{mcm}, a=8.87 \AA, c=12.65 \AA$; see Figure S1). Then we calculated the crystal surface energies, finding that the $(001)\left(E_{\mathrm{s}}\right.$ $\left.=1.6 \times 10^{-3} \mathrm{eV} / \AA^{2}\right),(100)\left(E_{\mathrm{s}}=3.5 \times 10^{-3} \mathrm{eV} / \AA^{2}\right)$, and (110) $\left(E_{\mathrm{s}}=4.7 \times 10^{-3} \mathrm{eV} / \AA^{2}\right)$ directions are the most stable configurations after relaxation (see Table S1). Side-views of the resulting structures of tetragonal $\mathrm{CH}_{3} \mathrm{NH}_{3} \mathrm{PbI}_{3}$ slabs along these stable orientations are shown in Figure 1c. Since the (001) and (110) directions show quite similar electronic properties, ${ }^{19}$ only the (001) and (100) directions will be considered for the sake of discussion. Data regarding the (110) orientation are available in the Supporting Information.

In the optimized crystal structure, the $\mathrm{Pb}-\mathrm{I}$ bond lengths were estimated to be $3.155,3.258$, and $3.278 \AA$, which compare well with crystal parameters of the same phase of $\mathrm{CH}_{3} \mathrm{NH}_{3} \mathrm{PbI}_{3}$ calculated previously without considering spin-orbit coupling (SOC)..$^{20,21}$ The band structure calculated using van der Waals density functional (vdW-DF2) for the optimized geometry shows a direct band gap energy of $E_{\mathrm{g}}=1.60 \mathrm{eV}$ at the $\Gamma$ point (Figure 1d). This value is slightly higher than the optical bandgap determined from the Tauc plot of experimental absorbance $\left(E_{\mathrm{g}}=1.58 \mathrm{eV}\right)$, but in good agreement with previous theoretical predictions. ${ }^{20}$ Inclusion of SOC lowers the band gap energy to $E_{\mathrm{g}}=0.52 \mathrm{eV}$ (Figure S2). While this could be corrected using a many body perturbation theory, e.g., the GW method, ${ }^{22}$ our interfacial structures are too large to be treated with GW calculations. Thus, the following studies of electronic properties of hybrid interfaces with the vdW-DF2 
function were conducted excluding SOC for heavy $\mathrm{Pb}$ atoms. This allows one to qualitatively follow the GW-SOC trends of different $\mathrm{CH}_{3} \mathrm{NH}_{3} \mathrm{PbI}_{3}$ surfaces, and to capture long-range dispersive interactions, which are useful to understand interfacial structures and physisorption in the hybrid systems. Compared to bulk $\mathrm{CH}_{3} \mathrm{NH}_{3} \mathrm{PbI}_{3}$, the optimized (001), (110) and (001) slabs generate similar conduction and valence bands, mainly consisting of a $5 \mathrm{p}$ orbital of I and a $6 \mathrm{p}$ orbital of $\mathrm{Pb}$. The band gaps are reduced only by $\sim 0.2 \mathrm{eV}$, despite the exclusion of SOC (Figure S2). Such reduction of the band gap energies is likely due to the presence of surface dangling bonds since the projected density of states of the organic compounds $\left(\mathrm{CH}_{3} \mathrm{NH}_{3}\right)$ at the surface of $\mathrm{CH}_{3} \mathrm{NH}_{3} \mathrm{PbI}_{3}$ contributes little to both top region of the valence band and bottom region of the conduction band ( $\mathrm{CB}$ ) in both bulk and slab cases.

Since the interaction between organic materials and perovskite is merely weak physisorption, our interfacial models were established by laying monolayer organic molecules (e.g., SpiroOMeTAD and PCBM) on top of optimized $\mathrm{CH}_{3} \mathrm{NH}_{3} \mathrm{PbI}_{3}$ slabs with preferred orientations (optimized interfacial structure coordinates are provided as Supporting Information in Tables $\mathrm{S} 2-\mathrm{S} 4)$. Note that the bonding energy between $\mathrm{Pb}$ and $\mathrm{I}$ dangling atoms on the surface of $\mathrm{CH}_{3} \mathrm{NH}_{3} \mathrm{PbI}_{3}$ and organic terminal groups is typically too small to promote the formation of chemical/covalent bonds with the adsorbed molecules. The energy levels and electronic cloud distribution of orbital wave functions across the hybrid interfaces between the organic materials and the different perovskite surfaces can be interpreted by the projected density of states (PDOS) after charge redistribution. The calculated total PDOS for the Spiro$\mathrm{OMeTAD} / \mathrm{CH}_{3} \mathrm{NH}_{3} \mathrm{PbI}_{3}$ interfaces (Figure 2a,b) can be decomposed into contributions from $\mathrm{CH}_{3} \mathrm{NH}_{3} \mathrm{PbI}_{3}$ and SpiroOMeTAD fragments (gray shaded areas in Figure 2a,b). For both perovskite surface orientations, the HOMO and HOMO1 (degenerated energy levels) of Spiro-OMeTAD are higher than the valence band maximum (VBM) of the perovskite, which would facilitate hole transfer toward the Spiro-OMeTAD

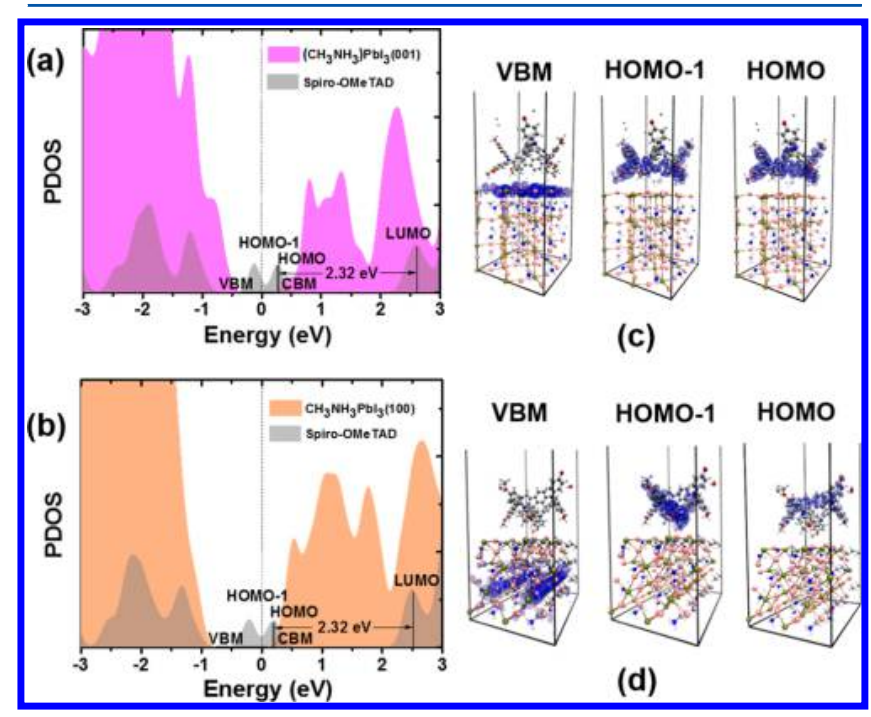

Figure 2. $(\mathrm{a}, \mathrm{b})$ Density of states of the Spiro-OMeTAD molecule on (a) $\mathrm{CH}_{3} \mathrm{NH}_{3} \mathrm{PbI}_{3}$ (001) and (b) $\mathrm{CH}_{3} \mathrm{NH}_{3} \mathrm{PbI}_{3}$ (100) surfaces (the vertical dashed line shows the Fermi energy level); (c,d) threedimensional representation of VBM, HOMO-1 and HOMO levels of (c) Spiro-OMeTAD $/ \mathrm{CH}_{3} \mathrm{NH}_{3} \mathrm{PbI}_{3}$ (001) and (d) Spiro-OMeTAD/ $\mathrm{CH}_{3} \mathrm{NH}_{3} \mathrm{PbI}_{3}(100)$ with an isovalue of $5 \times 10^{-4} \mathrm{e} / \AA^{3}$. layer, thereby increasing the efficiency of charge separation across the interface. On the other hand, the flow of electrons is effectively obstructed by the higher LUMO level of SpiroOMeTAD. While for the (001) orientation holes are preferentially distributed on the top surface of $\mathrm{CH}_{3} \mathrm{NH}_{3} \mathrm{PbI}_{3}$, with partial overlap to the HOMO (HOMO-1) electronic clouds localized on the organic branches of Spiro-OMeTAD, in the case of (100) orientation holes reside well below the perovskite-Spiro-OMeTAD interface. Thus, the (001) orientation yields stronger electronic cloud overlapping between perovskite and hole-transporting material, which would result in the formation of a hybrid interface state near the Fermi energy upon hole transfer. As anticipated, the nonpolar surface (110) also shows surface electronic distribution for VBM (Figure S3a in the Supporting Information), the same electronic features of surface (001) in combination with Spiro-OMeTAD. This finding is in agreement with recent theoretical results concluding that $\mathrm{CH}_{3} \mathrm{NH}_{3} \mathrm{PbI}_{3}$ (001) and (110) surfaces can be used as efficient intermediates for hole transfer. ${ }^{19}$

In experiments, charge separation at the heterojunction of $\mathrm{CH}_{3} \mathrm{NH}_{3} \mathrm{PbI}_{3}$ with the hole-transporting material was found to occur at time scales as short as $100 \mathrm{fs}$ after photoexcitation of the perovskite absorber. ${ }^{23}$ Photoinduced interfacial charge separation and relaxation processes in hybrid systems are typically addressed computationally by a combination of molecular dynamics and time-dependent DFT. ${ }^{24}$ Nevertheless, previous studies on hybrid systems (e.g., dye- $\mathrm{TiO}_{2}$ ) have shown that a purely molecular-dynamic approach may be sufficient to capture the photophysics of hybrid systems where adiabatic mechanisms dominate over nonadiabatic ones due to strong electronic coupling across the hybrid interface. ${ }^{25}$ According to this, we used Car-Parrinello molecular dynamic simulations to understand ground-state charge transfer process due to thermal fluctuations at room temperature. As shown in Figure 3, Spiro-

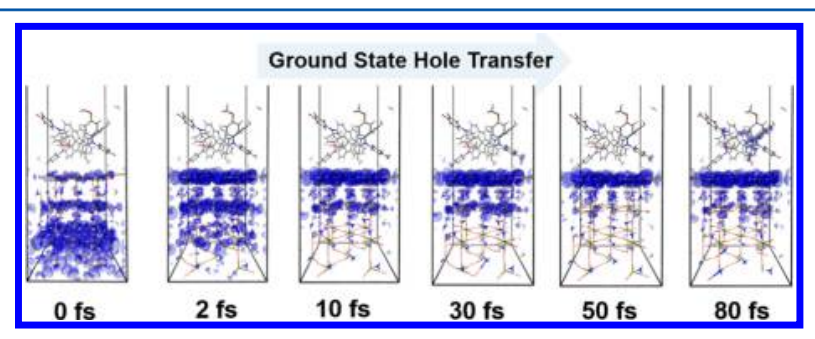

Figure 3. Car-Parrinello molecular dynamics simulation of the hole wave function distribution of Spiro-OMeTAD on a $\mathrm{CH}_{3} \mathrm{NH}_{3} \mathrm{PbI}_{3}$ (001) surface within the first $80 \mathrm{fs}$ from the beginning of ground-state relaxation, plotted at different time intervals with an isovalue of $5 \times$ $10^{-4} \mathrm{e} / \AA^{3}$.

OMeTAD on top of the $\mathrm{CH}_{3} \mathrm{NH}_{3} \mathrm{PbI}_{3}$ (001) begins to accumulate holes at $30 \mathrm{fs}$ from relaxation of the initial ground state as a result of the fluctuation of $\mathrm{VB}$ energy edge of $\mathrm{CH}_{3} \mathrm{NH}_{3} \mathrm{PbI}_{3}$ (001) and orbital overlapping with the HOMO level of Spiro-OMeTAD. Such short time is in line with the effective hole-transfer to Spiro-OMeTAD predicted from the hybridization of the perovskite $\mathrm{Pb} s-\mathrm{p}$ states and the HOMO orbitals at the interface (Figure $2 \mathrm{a}$ ). ${ }^{26}$ In other words, the surface-delocalized hole states in $\mathrm{CH}_{3} \mathrm{NH}_{3} \mathrm{PbI}_{3}$ (Figure 2c) enhance photoexcited charge transfer in the hybrid system. Conversely, in the case of Spiro-OMeTAD $/ \mathrm{CH}_{3} \mathrm{NH}_{3} \mathrm{PbI}_{3}$ (100) (Figure 2d), the weak overlap between the HOMO level of Spiro-OMeTAD and the VB of the perovskite suggests 
that hole transfer is hindered by the highly localized electronic distribution within the bulk of $\mathrm{CH}_{3} \mathrm{NH}_{3} \mathrm{PbI}_{3}$. Thus, the (001) and (110) orientations of $\mathrm{CH}_{3} \mathrm{NH}_{3} \mathrm{PbI}_{3}$ are deemed to be preferable to promote hole transfer to the hole extracting material in hybrid $\mathrm{CH}_{3} \mathrm{NH}_{3} \mathrm{PbI}_{3}$-based solar cell architectures.

Similar to the case of the Spiro-OMeTAD/CH $\mathrm{CH}_{3} \mathrm{NbI}_{3}$ system, surface orientation plays a key role in determining the electronic and charge transfer properties of electron-acceptor PCBM molecule on the $\mathrm{CH}_{3} \mathrm{NH}_{3} \mathrm{PbI}_{3}$ surfaces. The calculated LUMO of PCBM is located above the conduction band maximum $(\mathrm{CBM})$ of $\mathrm{CH}_{3} \mathrm{NH}_{3} \mathrm{PbI}_{3}$ (Figure $4 \mathrm{a}$ ) so that

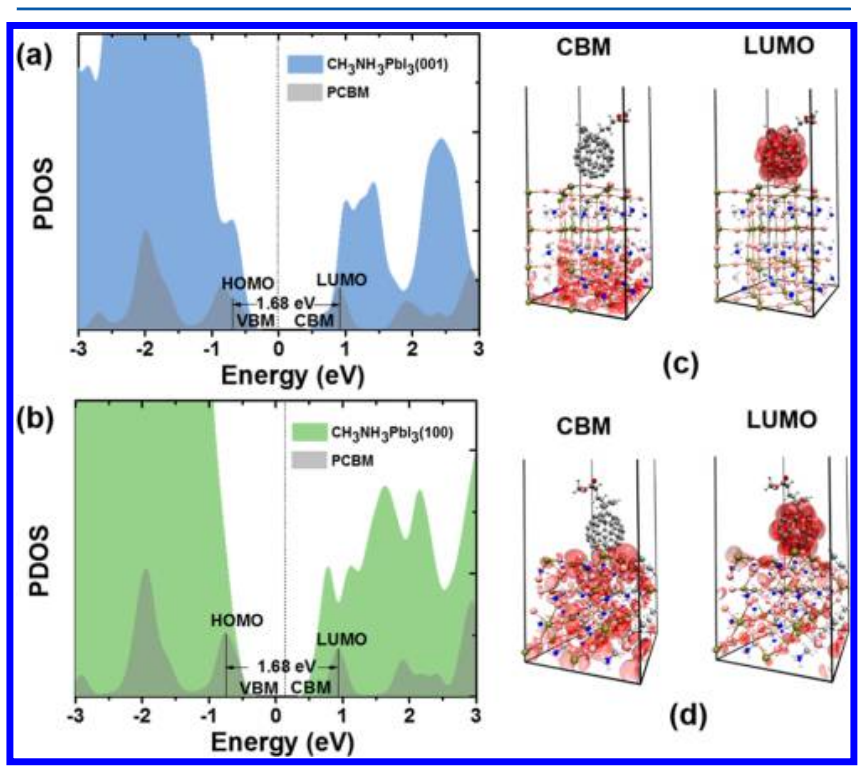

Figure 4. (a,b) Density of states of the PCBM molecule on (a) $\mathrm{CH}_{3} \mathrm{NH}_{3} \mathrm{PbI}_{3}$ (001) and (b) $\mathrm{CH}_{3} \mathrm{NH}_{3} \mathrm{PbI}_{3}$ (100) surfaces (the vertical dashed line shows the Fermi energy level); (c,d) three-dimensional representation of CBM and LUMO levels of (c) $\mathrm{PCBM} / \mathrm{CH}_{3} \mathrm{NH}_{3} \mathrm{PbI}_{3}$ (001) and (d) $\mathrm{PCBM} / \mathrm{CH}_{3} \mathrm{NH}_{3} \mathrm{PbI}_{3}(100)$ with isovalue of $5 \times 10^{-4}$ $\mathrm{e} / \AA^{3}$.

electrons can be effectively extracted from the perovskite into the PCBM layer, while holes are blocked. While the DFT method is known to underestimate band gap energies, it can still be used to accurately predict the electronic cloud distributions. For both nonpolar surfaces $\mathrm{CH}_{3} \mathrm{NH}_{3} \mathrm{PbI}_{3}(001)$ and (110), the CBM electronic distribution of $\mathrm{CH}_{3} \mathrm{NH}_{3} \mathrm{PbI}_{3}$ localizes below the surface, leading to the quite weak overlap with the LUMO of PCBM (Figure 4c and S3b). Differently, surface charges of $\mathrm{CH}_{3} \mathrm{NH}_{3} \mathrm{PbI}_{3}(100)$ at the VBM show a certain degree of electronic delocalization (Figure $4 \mathrm{~d}$ ), which provides overlap with localized charges at the LUMO level of PCBM. In this case, electrons could then easily leave the $\mathrm{CH}_{3} \mathrm{NH}_{3} \mathrm{PbI}_{3}$ and migrate to the PCBM.

Although hole and electron transfer are expected to be strongly dependent on electronic charge distribution of valence band maxima (VBM) or CBM of $\mathrm{CH}_{3} \mathrm{NH}_{3} \mathrm{PbI}_{3}$, the calculated energy alignments derived from the projected density of states turn out to be quite similar for the stable surface orientations. This is fortunate because it allows comparison of calculated energy levels with experimental UPS measurements of polycrystalline $\mathrm{CH}_{3} \mathrm{NH}_{3} \mathrm{PbI}_{3}$ films, which provide an ensemble average of the interfacial energetics of perovskite microcrystalline domains over all possible orientations. After performing UPS measurements of the organic/ $\mathrm{CH}_{3} \mathrm{NH}_{3} \mathrm{PbI}_{3}$ bilayers, the
VBM and work functions (WF) were determined from the VB onset in UPS spectra after baseline subtraction around the Fermi level (Figure S5). The obtained VBM and WF of $\mathrm{CH}_{3} \mathrm{NH}_{3} \mathrm{PbI}_{3}$, Spiro-OMeTAD and PCBM are in excellent agreement with previous experimental reports. ${ }^{6,27,28}$ The overall interfacial energy diagrams constructed combining UPS and optical data for $\mathrm{CH}_{3} \mathrm{NH}_{3} \mathrm{PbI}_{3} /$ Spiro-OMeTAD and $\mathrm{CH}_{3} \mathrm{NH}_{3} \mathrm{PbI}_{3} / \mathrm{PCBM}$ heterointerfaces are shown in Figure 5.

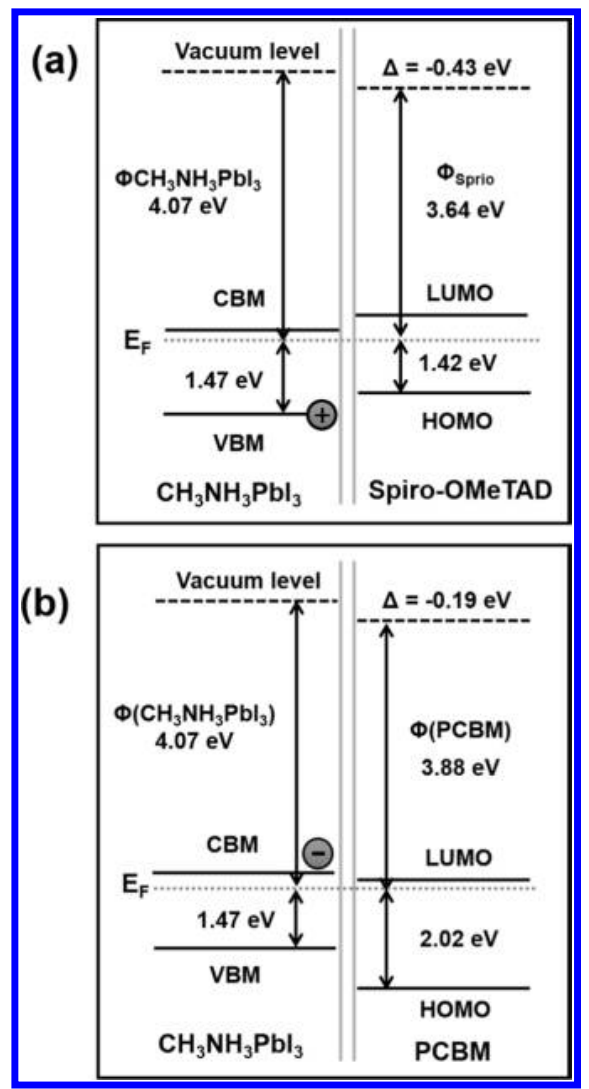

Figure 5. Relevant energy levels of (a) Spiro-OMeTAD $/ \mathrm{CH}_{3} \mathrm{NH}_{3} \mathrm{PbI}_{3}$ and (b) $\mathrm{PCBM} / \mathrm{CH}_{3} \mathrm{NH}_{3} \mathrm{PbI}_{3}$ derived from UPS measurements.

UPS data indicate the formation of type-II heterostructures in agreement with DFT calculations, which promote charge transfer from the perovskite to the organic layers. Note that the discontinuities of conduction $\left(\Delta_{\mathrm{e}}\right)$ and valence $\left(\Delta_{\mathrm{h}}\right)$ levels obtained experimentally for our $\sim 20 \mathrm{~nm}$ thick organic films reflect flat-band energy levels of the bulk, ${ }^{15}$ and are consistently smaller than interfacial discontinuities predicted from simulations of a single organic monolayer used to build the interfacial model (Figures 3 and 5).

To further quantify and compare the actual charge transferred between the different perovskite surfaces and the organic charge transporting materials, we evaluated the charge redistribution density and the corresponding electrostatic potential upon Spiro-OMeTAD or PCBM adsorption onto the $\mathrm{CH}_{3} \mathrm{NH}_{3} \mathrm{PbI}_{3}$ surfaces, and estimated the resulting interfacial dipole. ${ }^{29}$ The one-dimensional plane-averaged charge density differences $(\Delta \rho)$ and corresponding electrostatic potential along the vertical direction were plotted in Figure 6 to quantitatively describe the electron $(\Delta \rho<0)$ and hole $(\Delta \rho>$ $0)$ accumulation behavior. After charge redistribution when depositing Spiro-OMeTAD and PCBM, the main difference between $\mathrm{CH}_{3} \mathrm{NH}_{3} \mathrm{PbI}_{3}$ surfaces (001) and (100) is that more 


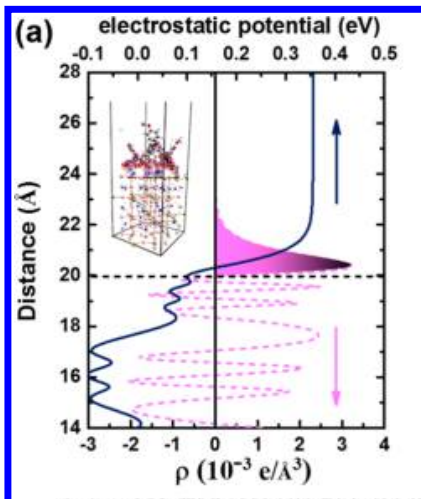

Spiro-OMeTAD/CH $\mathrm{NH}_{3} \mathrm{Pbl}_{3}(001)$

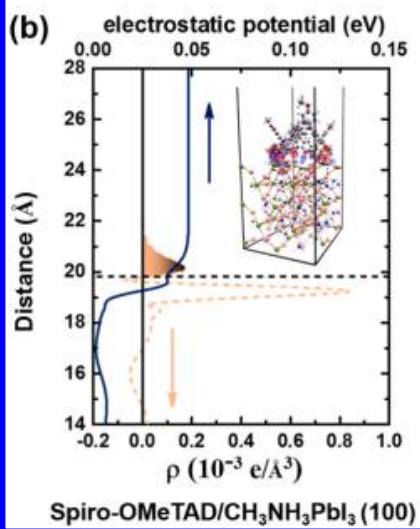

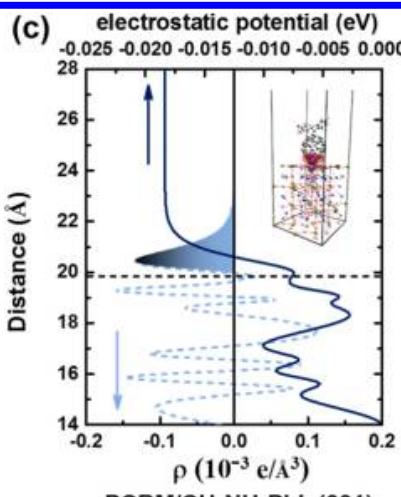

$\mathrm{PCBM} / \mathrm{CH}_{3} \mathrm{NH}_{3} \mathrm{Pbl}_{3}(001)$

(d) electrostatic potential $(\mathrm{eV})$
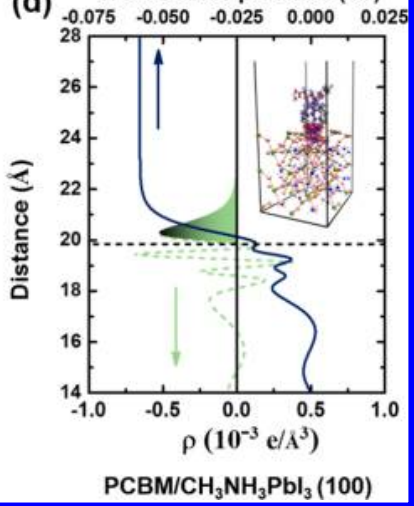

Figure 6. One-dimensional plane-averaged charge density differences (defined as $\rho_{\text {diff }}=\rho_{\text {total }}-\rho_{\text {per }}-\rho_{\text {Spiro/PCBM }}, \rho_{\text {total }}$ is the total charge density of the heterojunction, and $\rho_{\text {per }}, \rho_{\text {PCBM }}$, and $\rho_{\text {Sprio }}$ represent the charge density of the individual parts) and induced electrostatic potential at (a) Spiro-OMeTAD $/ \mathrm{CH}_{3} \mathrm{NH}_{3} \mathrm{PbI}_{3}$ (001); (b) SpiroOMeTAD $/ \mathrm{CH}_{3} \mathrm{NH}_{3} \mathrm{PbI}_{3}$ (100); (c) PCBM $/ \mathrm{CH}_{3} \mathrm{NH}_{3} \mathrm{PbI}_{3}$ (001), and (d) $\mathrm{PCBM} / \mathrm{CH}_{3} \mathrm{NH}_{3} \mathrm{PbI}_{3}$ (100) interfaces. Three-dimensional representations of the charge density difference are inserted with isovalue of $5 \times 10^{-4} \mathrm{e} / \AA^{3}$. The green lines represent the electrostatic potential across the interface.

holes accumulate above the (001) or (110) surface interacting with the Spiro-OMeTAD molecule, and more electrons accumulate at the $\mathrm{PCBM} / \mathrm{CH}_{3} \mathrm{NH}_{3} \mathrm{PbI}_{3}$ (100) interface. These positive or negative charge accumulation layers reduce electrostatic screening, favoring charge exchange between organic transporting materials and $\mathrm{CH}_{3} \mathrm{NH}_{3} \mathrm{PbI}_{3}$. Quantitatively, the charge density above the $\mathrm{CH}_{3} \mathrm{NH}_{3} \mathrm{PbI}_{3}$ surface was compared by integrating the surface components of $\Delta \rho$ (shaded areas in Figure 6): total surface-accumulated positive charge densities of $2.99 \times 10^{13} \mathrm{e} / \mathrm{cm}^{2}$ and $9.20 \times 10^{11} \mathrm{e} / \mathrm{cm}^{2}$ are obtained for Spiro-OMeTAD/ $\mathrm{CH}_{3} \mathrm{NH}_{3} \mathrm{PbI}_{3}$ (001) and (100) surfaces, respectively. This indicates a much larger hole accumulation in the case of (001) surface, mostly due to the large charge displacement between the methoxybenzene $\left(\mathrm{CH}_{3} \mathrm{OC}_{6} \mathrm{H}_{5}\right)$ group and surface $\mathrm{Pb}$ atoms. A similar charge displacement is obtained at the $\mathrm{PCBM} / \mathrm{CH}_{3} \mathrm{NH}_{3} \mathrm{PbI}_{3}$ interface: the negative charge densities accumulated toward $\mathrm{CH}_{3} \mathrm{NH}_{3} \mathrm{PbI}_{3}$ are respectively $-1.27 \times 10^{12} \mathrm{e} / \mathrm{cm}^{2}$ and $-3.25 \times 10^{12} \mathrm{e} / \mathrm{cm}^{2}$ for the (001) and (100) surfaces.

The electrostatic potential, plotted as a solid green line in Figure 6, offers additional information on how the organic charge transporting materials affect the local charge redistribution upon formation of the hybrid interface. In the case of Spiro-OMeTAD/CH $\mathrm{CH}_{3} \mathrm{NbI}_{3}$ (001) or (110), the large potential increase observed at the interface, which attracts more holes than electrons, benefits interfacial electron-hole pair dissociation. On the other hand, the presence of PCBM causes a potential drop in the case of the (100) surface, which attracts more electrons than holes. According to their real-space analysis, Berger and co-workers suggested that the electrical potential barrier formed upon accumulation of excess holes may be a serious bottleneck to improving device efficiency. ${ }^{12}$ Experimental determination of the work functions by UPS measurements confirms the formation of interfacial dipole barriers of $0.43 \mathrm{eV}$ for Spiro-OMeTAD/CH $\mathrm{CH}_{3} \mathrm{NH}_{3} \mathrm{PbI}_{3}$ and 0.19 $\mathrm{eV}$ for $\mathrm{PCBM} / \mathrm{CH}_{3} \mathrm{NH}_{3} \mathrm{PbI}_{3}$, resulting from the displacement of positive charge from $\mathrm{CH}_{3} \mathrm{NH}_{3} \mathrm{PbI}_{3}$ to Spiro-OMeTAD and negative charge from $\mathrm{CH}_{3} \mathrm{NH}_{3} \mathrm{PbI}_{3}$ to $\mathrm{PCBM}$, respectively. The vacuum level shift induced by the interfacial dipole can be deduced from comparison of the interfacial electrostatic potential $(\Delta \Phi)$ between the $\mathrm{CH}_{3} \mathrm{NH}_{3} \mathrm{PbI}_{3}$ surface and the organic molecular plane using the Helmholtz equation $\Delta \Phi=$ $\mu n / \varepsilon_{0}$ (here $\mu$ is the interface dipole moment, i.e., the amount of excess of charge obtained from integrating $\Delta \rho$ from the origin to the point where charge depletion switches to charge accumulation; $n=1 / A$, where $A$ is the surface area of the interface) $)^{30}$ The values of $\Delta \Phi$ of $\sim 0.09$ and $\sim 0.04 \mathrm{eV}$ obtained for Spiro-OMeTAD/C $\mathrm{CH}_{3} \mathrm{NH}_{3} \mathrm{PbI}_{3}$ and $\mathrm{PCBM} / \mathrm{CH}_{3} \mathrm{NH}_{3} \mathrm{PbI}_{3}$ system are somewhat smaller than the interfacial dipole barriers observed in experiments due to the monolayer thickness used in simulations; however, the relative magnitude of electron and hole interfacial dipoles is well reproduced. Therefore, we are confident that our hybrid interfacial model could be widely applied to search for new charge transporting materials to overcome the charge extraction bottleneck in hybrid perovskite solar cells.

In summary, we studied interfacial energy alignment and charge transfer properties between lead iodide perovskite $\mathrm{CH}_{3} \mathrm{NH}_{3} \mathrm{PbI}_{3}$ and organic charge transporting layers SpiroOMeTAD and PCBM, which are commonly employed in solar cell devices. Our theoretical results agree well with experimental UPS measurements, showing that nonpolar $\mathrm{CH}_{3} \mathrm{NH}_{3} \mathrm{PbI}_{3}$ (001) and (110) surface tends to favor hole injection into Spiro-OMeTAD, and polar $\mathrm{CH}_{3} \mathrm{NH}_{3} \mathrm{PbI}_{3}$ (100) surface tends to facilitate electron transfer to PCBM due to largely delocalized surface states and orbital coupling. We predict the presence of hole/electron accumulation layers at the $\mathrm{CH}_{3} \mathrm{NH}_{3} \mathrm{PbI}_{3}$ with different orientations, which result in the formation of large interfacial dipole moments at the organic/ perovskite interface. We believe these findings should apply to a wider range of organic/perovskite interfaces, pointing to the importance of perovskite crystallization and surface orientation to optimize not only transport parameters, but also charge transfer properties. We suggest that surface functionalization by grafted terminal groups could provide additional routes to increase the intrinsic interfacial dipole moments and optimize hybrid perovskite photovoltaic performance.

\section{EXPERIMENTAL METHODS}

Computational Approach. The geometry optimizations and electronic structures have been carried out by the Perdew, Burke, and Ernzerhof (PBE) generalized gradient approximation (GGA) performed by using the Quantum ESPRESSO. ${ }^{31}$ Electron-ion interactions were described by ultrasoft pseudopotentials with electrons from $\mathrm{H}\left(1 \mathrm{~s}^{1}\right) ; \mathrm{O}, \mathrm{N}$ and $\mathrm{C}\left(2 \mathrm{~s}^{2}, 2 \mathrm{p}^{2}\right)$; I $\left(5 \mathrm{~s}^{2}, 5 \mathrm{p}^{2}\right) ; \mathrm{Pb}\left(5 \mathrm{~d}^{10}, 6 \mathrm{~s}^{2}, 6 \mathrm{p}^{2}\right)$, shells explicitly included in the calculations. ${ }^{32}$ Single-particle wave functions (charges) are 
expanded on a plane-wave basis set up to a kinetic energy cutoff of $40 \mathrm{Ry}$ (300 Ry) for unit slabs and $25 \mathrm{Ry}$ (200 Ry) for large interfacial structures to acquire computational modeling of the interface considering accurate and computational points. The vdW-DF2 functional ${ }^{33,34}$ that accounts for dispersion effects self-consistently was also used for electronic calculations since dispersion forces have a significant additive stabilization effect on the charge transfer systems. ${ }^{35,36}$ The Monkhort-Pack type $\mathrm{k}$-meshes is $4 \times 4 \times 2$ for the tetragonal phase of bulk $\mathrm{CH}_{3} \mathrm{NH}_{3} \mathrm{PbI}_{3}$. A regular $(4 \times 4)$ grid of $\mathrm{k}$-points is used to sample the $2 \mathrm{D}$ Brillouin zone of the slab cell and $(2 \times 2)$ for organic/perovskite interfaces. All systems are simulated using periodically repeated supercells. The unit cells have a $(2 \times 2)$ lateral periodicity and contain four bilayers of $\mathrm{CH}_{3} \mathrm{NH}_{3} \mathrm{PbI}_{3}$ exposing the (001) and (100) surface. Slab replicas are separated by $\sim 15 \AA$ of vacuum. Each structure is optimized until forces on single atoms are smaller than $0.02 \mathrm{eV} / \AA$. The ground state charge transfer taking place in the electronic ground state was considered in this study. Car-Parrinello (CP) molecular dynamics ${ }^{37}$ was used to study the thermal fluctuations effect on the ground state charge transfer at the hybrid interfaces. The fictitious electron mass was 500 au and a time step of 0.121 fs was used. The the interfacial structure of $\mathrm{CH}_{3} \mathrm{NH}_{3} \mathrm{PbI}_{3} /$ Spiro-OMeTAD was initially optimized to an energy minimum by static relaxation. This interfacial system was then optimized using damped dynamics for both ions and electrons within 100 fs and subsequently heated up to $300 \mathrm{~K}$ with a $100 \mathrm{fs}$ molecular dynamics run, and then maintained at $300 \mathrm{~K}$ for $1000 \mathrm{fs}$ to reach thermal equilibrium. Finally, another $1000 \mathrm{fs} \mathrm{MD}$ production run was performed, and six selected electronic structures were recorded during the first $100 \mathrm{fs}$ trajectory. The molecular graphics viewer VDM and VESTA were used to plot molecular structures and wave functions. ${ }^{38}$

Sample Preparation. Methylammonium iodide $\mathrm{CH}_{3} \mathrm{NH}_{3} \mathrm{I}$ was prepared by mixing in a $10 \mathrm{~mL}$ round-bottom flask $15 \mathrm{~mL}$ of methylamine solution $\left(\mathrm{CH}_{3} \mathrm{NH}_{2}, 40 \%\right.$ in methanol, TCI $)$ and $14 \mathrm{~mL}$ of hydroiodic acid ( $57 \mathrm{wt} \%$ in water). The solution was kept in an ice bath and stirred for $2 \mathrm{~h}$, then the solvent was removed using a rotary evaporator $\left(1 \mathrm{~h}\right.$ at $60 \mathrm{mbar}$ and $\left.60{ }^{\circ} \mathrm{C}\right)$. The resultant precipitate was dissolved in ethanol and recrystallized from diethyl ether. The washing step was repeated six times, and the white powder collected was dried in vacuum oven at $60{ }^{\circ} \mathrm{C}$ for $24 \mathrm{~h}$. Powders of methylammonium lead iodide were prepared mixing $0.395 \mathrm{~g}$ of $\mathrm{CH}_{3} \mathrm{NH}_{3} \mathrm{I}$ and $1.157 \mathrm{~g}$ of $\mathrm{PbI}_{2}$ (99\%, Sigma-Aldrich) in $2 \mathrm{~mL}$ of DMF. The solution was left overnight at $60{ }^{\circ} \mathrm{C}$ in a $10 \mathrm{~mL}$ round-bottom flask under magnetic stirring and nitrogen flux. The solvent was removed with a rotary evaporator $(2 \mathrm{~h}$ at 30 mbar and $80{ }^{\circ} \mathrm{C}$ ), and the collected powder was dried in a vacuum oven for $12 \mathrm{~h}$ at $100{ }^{\circ} \mathrm{C}$. Thin films of $\mathrm{CH}_{3} \mathrm{NH}_{3} \mathrm{PbI}_{3}$ were fabricated on p-doped silicon by spin coating technique in $\mathrm{N}_{2}$ atmosphere. The substrates were cleaned with $10 \mathrm{~min}$ of sonication in acetone, IPA and exposed to $\mathrm{O}_{2}$ plasma for 20 min. $\mathrm{CH}_{3} \mathrm{NH}_{3} \mathrm{I}(49.5 \mathrm{mg})$ and $\mathrm{PbI}_{2}(144.5 \mathrm{mg})$ were mixed in 1 $\mathrm{mL}$ of $\gamma$-butyrolactone and stirred overnight at $60{ }^{\circ} \mathrm{C}$. The solution was spin-coated using a 3 steps ramp: $1000 \mathrm{rpm}$ for 60 $\mathrm{s}, 2000 \mathrm{rpm}$ for $60 \mathrm{~s}$ and $4000 \mathrm{rpm}$ for $60 \mathrm{~s}$. The films were then annealed at $100{ }^{\circ} \mathrm{C}$ for $30 \mathrm{~min}$. Spiro-OMeTAD (50 mg/ $\mathrm{mL}$ in chlorobenzene) and PCBM $(10 \mathrm{mg} / \mathrm{mL}$ in chlorobenzene) were spin coated on top of the perovskite layer at $4000 \mathrm{rpm}$ for $30 \mathrm{~s}$.

XRD Measurements. The diffractometer BRUKER D8 ADVANCE with Bragg-Brentano geometry was used for the
$\mathrm{X}$-ray characterization, using the $\mathrm{Cu} \mathrm{K} \alpha$ radiation $(l=1.54056$ $\AA)$, with step increment of $0.02^{\circ}$ and $1 \mathrm{~s}$ of acquisition time. The Pawley fit was done with TOPAS 3.0 using the lattice parameter for the tetragonal structure and space group $I 4 / \mathrm{mcm}$ previously reported. The peak profile and the background were fit respectively with a TCHZ Pseudo-Voigt function and a Chebichev polynomial of fifth order with $1 / x$ function. The refined parameters were the zero error, scale factor, linear absorption coefficient, and lattice parameters.

UPS Spectroscopy. UPS measurements are used to investigate the energy level alignments of organic/ $\mathrm{CH}_{3} \mathrm{NH}_{3} \mathrm{PbI}_{3}$ interfaces. Spiro-OMeTAD and PCBM were dissolved in chlorobenzene $(50 \mathrm{mg} / \mathrm{mL})$ and spin-coated on the p-doping Si substrates with $\mathrm{CH}_{3} \mathrm{NH}_{3} \mathrm{PbI}_{3}$ at $2000 \mathrm{rpm}$ for $60 \mathrm{~s}$ and resulting thickness of Spiro-OMeTAD or PCBM is about $20 \mathrm{~nm}$ from atomic force microscopy measurements. After deposition, the samples were thermally annealed at $150{ }^{\circ} \mathrm{C}$ for $20 \mathrm{~min}$ in inert atmosphere of nitrogen gas. UPS measurements were performed under high vacuum with excitation of $\mathrm{He} \mathrm{I}(h \nu=21.2 \mathrm{eV})$.

\section{ASSOCIATED CONTENT}

\section{S Supporting Information}

$\mathrm{X}$-ray diffractogram of $\mathrm{CH}_{3} \mathrm{NH}_{3} \mathrm{PbI}_{3}$ powders, surface energies and density of states for different $\mathrm{CH}_{3} \mathrm{NH}_{3} \mathrm{PbI}_{3}$ slabs, projected density of states and charge density differences of Spiro$\mathrm{OMeTAD} / \mathrm{CH}_{3} \mathrm{NH}_{3} \mathrm{PbI}_{3}$ (110) and $\mathrm{PCBM} / \mathrm{CH}_{3} \mathrm{NH}_{3} \mathrm{PbI}_{3}$ (110), UPS spectra, and optimized interfacial structural coordinates. This material is available free of charge via the Internet at http://pubs.acs.org.

\section{AUTHOR INFORMATION}

\section{Corresponding Author}

*E-mail: csoci@ntu.edu.sg.

\section{Notes}

The authors declare no competing financial interest.

\section{ACKNOWLEDGMENTS}

Research was supported by the NTU NAP startup grant (M4080511), the Singapore Ministry of Education (MOE2013T2-1-044), and the Singapore-Berkeley Research Initiative for Sustainable Energy (SinBeRISE) Create Programme. The authors are grateful to $\mathrm{Li}$ Shuzhou for comments and suggestions regarding the manuscript.

\section{REFERENCES}

(1) Hodes, G.; Cahen, D. Perovskite Cells Roll Forward. Nat. Photonics 2014, 8, 87-88.

(2) Snaith, H. J. Perovskites: The Emergence of a New Era for LowCost, High-Efficiency Solar Cells. J. Phys. Chem. Lett. 2013, 4, 36233630.

(3) Kojima, A.; Teshima, K.; Shirai, Y.; Miyasaka, T. Organometal Halide Perovskites as Visible-Light Sensitizers for Photovoltaic Cells. J. Am. Chem. Soc. 2009, 131, 6050-6051.

(4) Lee, M. M.; Teuscher, J.; Miyasaka, T.; Murakami, T. N.; Snaith, H. J. Efficient Hybrid Solar Cells Based on Meso-Superstructured Organometal Halide Perovskites. Science 2012, 338, 643-647.

(5) Zhou, H.; Chen, Q.; Li, G.; Luo, S.; Song, T.-b.; Duan, H.-S.; Hong, Z.; You, J.; Liu, Y.; Yang, Y. Interface Engineering of Highly Efficient Perovskite Solar Cells. Science 2014, 345, 542-546.

(6) Kim, H. S.; Lee, C. R.; Im, J. H.; Lee, K. B.; Moehl, T.; Marchioro, A.; Moon, S. J.; Humphry-Baker, R.; Yum, J. H.; Moser, J. E.; et al. Lead Iodide Perovskite Sensitized All-Solid-State Submicron Thin Film Mesoscopic Solar Cell with Efficiency Exceeding 9\%. Sci. Rep 2012, 2, 591. 
(7) Burschka, J.; Pellet, N.; Moon, S. J.; Humphry-Baker, R.; Gao, P.; Nazeeruddin, M. K.; Gratzel, M. Sequential Deposition as a Route to High-Performance Perovskite-Sensitized Solar Cells. Nature 2013, 499, 316-319.

(8) Chin, X. Y.; Cortecchia, D.; Yin, J.; Bruno, A.; Soci, C. Lead Iodide Perovskite Light-Emitting Field-Effect Transistor. 2015, arXiv:1501.04407.

(9) Stranks, S. D.; Eperon, G. E.; Grancini, G.; Menelaou, C.; Alcocer, M. J. P.; Leijtens, T.; Herz, L. M.; Petrozza, A.; Snaith, H. J. Electron-Hole Diffusion Lengths Exceeding 1 Micrometer in an Organometal Trihalide Perovskite Absorber. Science 2013, 342, 341344.

(10) Xing, G. C.; Mathews, N.; Sun, S. Y.; Lim, S. S.; Lam, Y. M.; Gratzel, M.; Mhaisalkar, S.; Sum, T. C. Long-Range Balanced Electronand Hole-Transport Lengths in Organic-Inorganic $\mathrm{CH}_{3} \mathrm{NH}_{3} \mathrm{PbI}_{3}$. Science 2013, 342, 344-347.

(11) Lindblad, R.; Bi, D. Q.; Park, B. W.; Oscarsson, J.; Gorgoi, M.; Siegbahn, H.; Odelius, M.; Johansson, E. M. J.; Rensmo, H. Electronic Structure of $\mathrm{TiO}_{2} / \mathrm{CH}_{3} \mathrm{NH}_{3} \mathrm{PbI}_{3}$ Perovskite Solar Cell Interfaces. J. Phys. Chem. Lett. 2014, 5, 648-653.

(12) Bergmann, V. W.; Weber, S. A. L.; Ramos, F. J.; Nazeeruddin, M. K.; Gratzel, M.; Li, D.; Domanski, A. L.; Lieberwirth, I.; Ahmad, S.; Berger, R. Real-Space Observation of Unbalanced Charge Distribution inside a Perovskite-Sensitized Solar Cell. Nat. Commun. 2014, 5, 5001.

(13) Jeon, N. J.; Noh, J. H.; Kim, Y. C.; Yang, W. S.; Ryu, S.; Il Seol, $S$. Solvent Engineering for High-Performance Inorganic-Organic Hybrid Perovskite Solar Cells. Nat. Mater. 2014, 13, 897-903.

(14) Grancini, G.; Marras, S.; Prato, M.; Giannini, C.; Quarti, C.; De Angelis, F.; De Bastiani, M.; Eperon, G. E.; Snaith, H. J.; Manna, L.; et al. The Impact of the Crystallization Processes on the Structural and Optical Properties of Hybrid Perovskite Films for Photovoltaics. J. Phys. Chem. Lett. 2014, 5, 3836-3842.

(15) Schulz, P.; Edri, E.; Kirmayer, S.; Hodes, G.; Cahen, D.; Kahn, A. Interface Energetics in Organo-Metal Halide Perovskite-Based Photovoltaic Cells. Energy Environ. Sci. 2014, 7, 1377-1381.

(16) Wehrenfennig, C.; Eperon, G. E.; Johnston, M. B.; Snaith, H. J.; Herz, L. M. High Charge Carrier Mobilities and Lifetimes in Organolead Trihalide Perovskites. Adv. Mater. 2014, 26, 1584-1589.

(17) Shi, D.; Adinolfi, V.; Comin, R.; Yuan, M. J.; Alarousu, E.; Buin, A.; Chen, Y.; Hoogland, S.; Rothenberger, A.; Katsiev, K.; et al. Low Trap-State Density and Long Carrier Diffusion in Organolead Trihalide Perovskite Single Crystals. Science 2015, 347, 519-522.

(18) Nie, W.; Tsai, H.; Asadpour, R.; Blancon, J. C.; Neukirch, A. J.; Gupta, G.; Crochet, J. J.; Chhowalla, M.; Tretiak, S.; Alam, M. A.; et al. High-Efficiency Solution-Processed Perovskite Solar Cells with Millimeter-Scale Grains. Science 2015, 347, 522-525.

(19) Haruyama, J.; Sodeyama, K.; Han, L. Y.; Tateyama, Y. Termination Dependence of Tetragonal $\mathrm{CH}_{3} \mathrm{NH}_{3} \mathrm{PbI}_{3}$ Surfaces for Perovskite Solar Cells. J. Phys. Chem. Lett. 2014, 5, 2903-2909.

(20) Geng, W.; Zhang, L.; Zhang, Y. N.; Lau, W. M.; Liu, L. M. FirstPrinciples Study of Lead Iodide Perovskite Tetragonal and Orthorhombic Phases for Photovoltaics. J. Phys. Chem. C 2014, 118, 19565-19571.

(21) Torres, A.; Rego, L. G. C. Surface Effects and Adsorption of Methoxy Anchors on Hybrid Lead Iodide Perovskites: Insights for Spiro-Meotad Attachment. J. Phys. Chem. C 2014, 118, 26947-26954.

(22) Umari, P.; Mosconi, E.; De Angelis, F. Relativistic GW Calculations on $\mathrm{CH}_{3} \mathrm{NH}_{3} \mathrm{PbI}_{3}$ and $\mathrm{CH}_{3} \mathrm{NH}_{3} \mathrm{SnI}_{3}$ Perovskites for Solar Cell Applications. Sci. Rep 2014, 4, 4467.

(23) Marchioro, A.; Teuscher, J.; Friedrich, D.; Kunst, M.; van de Krol, R.; Moehl, T.; Gratzel, M.; Moser, J. E. Unravelling the Mechanism of Photoinduced Charge Transfer Processes in Lead Iodide Perovskite Solar Cells. Nat. Photonics 2014, 8, 250-255.

(24) Akimov, A. V.; Neukirch, A. J.; Prezhdo, O. V. Theoretical Insights into Photoinduced Charge Transfer and Catalysis at Oxide Interfaces. Chem. Rev. 2013, 113, 4496-4565.

(25) Duncan, W. R.; Craig, C. F.; Prezhdo, O. V. Time-Domain Ab Initio Study of Charge Relaxation and Recombination in DyeSensitized $\mathrm{TiO}_{2}$. J. Am. Chem. Soc. 2007, 129, 8528-8543.
(26) Roiati, V.; Mosconi, E.; Listorti, A.; Colella, S.; Gigli, G.; De Angelis, F. Stark Effect in Perovskite/ $/ \mathrm{TiO}_{2}$ Solar Cells: Evidence of Local Interfacial Order. Nano Lett. 2014, 14, 2168-2174.

(27) Tada, A.; Geng, Y. F.; Wei, Q. S.; Hashimoto, K.; Tajima, K. Tailoring Organic Heterojunction Interfaces in Bilayer Polymer Photovoltaic Devices. Nat. Mater. 2011, 10, 450-455.

(28) Wang, Q. K.; Wang, R. B.; Shen, P. F.; Li, C.; Li, Y. Q.; Liu, L. J.; Duhm, S.; Tang, J. X. Energy Level Offsets at Lead Halide Perovskite/ Organic Hybrid Interfaces and Their Impacts on Charge Separation. Adv. Mater. Interfaces 2015, 2, 1400528.

(29) Yin, J.; Migas, D. B.; Panahandeh-Fard, M.; Chen, S.; Wang, Z. L.; Lova, P.; Soci, C. Charge Redistribution at GaAs/P3HT Heterointerfaces with Different Surface Polarity. J. Phys. Chem. Lett. 2013, 4, 3303-3309.

(30) Sai, N.; Gearba, R.; Dolocan, A.; Tritsch, J. R.; Chan, W. L.; Chelikowsky, J. R.; Leung, K.; Zhu, X. Y. Understanding the Interface Dipole of Copper Phthalocyanine $(\mathrm{CuPc}) / \mathrm{C}_{60}$ : Theory and Experiment. J. Phys. Chem. Lett. 2012, 3, 2173-2177.

(31) Giannozzi, P.; Baroni, S.; Bonini, N.; Calandra, M.; Car, R.; Cavazzoni, C.; Ceresoli, D.; Chiarotti, G. L.; Cococcioni, M.; Dabo, I.; et al. Quantum Espresso: A Modular and Open-Source Software Project for Quantum Simulations of Materials. J. Phys.: Condens. Matter 2009, 21, 395502.

(32) Garrity, K. F.; Bennett, J. W.; Rabe, K. M.; Vanderbilt, D. Pseudopotentials for High-Throughput DFT Calculations. Comput. Mater. Sci. 2014, 81, 446-452.

(33) Roman-Perez, G.; Soler, J. M. Efficient Implementation of a van der Waals Density Functional: Application to Double-Wall Carbon Nanotubes. Phys. Rev. Lett. 2009, 103, 096102.

(34) Lee, K.; Murray, E. D.; Kong, L. Z.; Lundqvist, B. I.; Langreth, D. C. Higher-Accuracy van der Waals Density Functional. Phys. Rev. B 2010, 82, 081101.

(35) Thonhauser, T.; Cooper, V. R.; Li, S.; Puzder, A.; Hyldgaard, P.; Langreth, D. C. van der Waals Density Functional: Self-Consistent Potential and the Nature of the van der Waals Bond. Phys. Rev. B 2007, $76,11$.

(36) Dion, M.; Rydberg, H.; Schroder, E.; Langreth, D. C.; Lundqvist, B. I. van der Waals Density Functional for General Geometries. Phys. Rev. Lett. 2004, 92, 246401.

(37) Car, R.; Parrinello, M. Unified Approach for MolecularDynamics and Density-Functional Theory. Phys. Rev. Lett. 1985, 55, 2471-2474.

(38) Humphrey, W.; Dalke, A.; Schulten, K. VMD: Visual Molecular Dynamics. J. Mol. Graph. 1996, 14, 33-38. 